\title{
Relationship between relative age effect and physical characteristics of young soccer players
}

\author{
Relación entre el efecto de la edad relativa y las características físicas de los jóvenes \\ jugadores de fútbol
}

\author{
Celso Jose Silva Junior ${ }^{1}$, Alexandre Palma ${ }^{1}$, Luis Aureliano Imbiriba ${ }^{1}$, Monique Ribeiro Assis ${ }^{2}$, Marcio \\ Assis Marques Barbosa ${ }^{3}$
}

1 Escola de Educação Física e Desportos. Universidade Federal do Rio de Janeiro. Brasil.

2 Escola de Educação Física e Desportos. Universidade Gama Filho. Brasil.

3 Fluminense Football Club. Brasil.

CORRESPONDENCIA:

Celso Jose Silva Junior

Recepción: noviembre 2013・Aceptación: julio 2015

celsinhosilva@hotmail.com

\begin{abstract}
The junior categories of sports generally represent a particular period of extreme complexity for children and young sports players, since this time coincides precisely with the phase of puberty. During this period, there are great changes to body size and composition, as well as changes to the functional capacity of children and adolescents. In addition, the literature points towards another complicating factor observed among young soccer players: relative age. The objectives of the present study were: a) to observe the distribution of dates of birth among junior soccer players over the course of the trimesters of the year; b) to compare the players' anthropometric characteristics and physical performance according to the trimester of birth; and c) to analyze the influence of the maturity offset in the process of selecting young players. Eighty-nine male soccer players from the under-14s category participated in this study. The physical tests applied were weight, height, maturity offset, $10 \mathrm{~m}$ sprint, $30 \mathrm{~m}$ sprint and Running-based Anaerobic Sprint Test (RAST). It should be noted that there was a great imbalance in the distribution of dates of birth, with an especially large presence of individuals born in the first half of the year $(p<0.001)$. Anthropometric, physical and maturational characteristics were compared according to the trimester of birth and statistically significant differences were observed only in comparing the maturity offset $(p<0.005)$. It can be concluded that the trimester of birth may not have a relationship with physical performance and anthropometric characteristics, even if there are differences in biological maturation.
\end{abstract}

Key words: Sports, youth, physical performance, biological maturation.

\section{Resumen}

Las categorías inferiores de los deportes generalmente representan un determinado período de extrema complejidad en niños y jóvenes deportistas, ya que coincide precisamente con la fase de la pubertad. Durante este período, hay grandes modificaciones en el tamaño y la composición corporal, así como cambios en la capacidad funcional en niños y adolescentes. Además, la literatura presenta otro factor de complicación observado entre los jóvenes futbolistas: la edad relativa. Los objetivos del presente artículo fueron: a) observar la distribución de las fechas de nacimiento de los jóvenes jugadores de fútbol, de acuerdo a los trimestres del año; b) comparar las características antropométricas de los jugadores y el rendimiento físico de acuerdo con el trimestre de nacimiento, y c) analizar la influencia de la maduración en el proceso de selección de jugadores jóvenes. Ochenta y nueve jugadores de fútbol masculino de la categoría sub-14 participaron en este artículo. Los tests físicos aplicados fueron: de peso, estatura, maduración biológica, sprint de 10 metros, sprint de 30 metros y el Running-based Anaerobic Sprint Test (RAST). Hubo un gran desequilibrio en la distribución de las fechas de nacimiento, especialmente con gran presencia en las personas nacidas en la primera mitad del año $(p<0.001)$. Las características antropométricas,

físicas y de maduración se compararon según el trimestre de nacimiento y las diferencias estadísticamente significativas se observaron sólo en la comparación con la maduración $(p<0.005)$. Se puede concluir que el trimestre de nacimiento no presenta relación con el rendimiento físico ni con las características antropométricas, aunque sí hay diferencias en la maduración biológica.

Palabras clave: deportes, juvenil, desempeño físico, maduración biológica. 


\section{Introduction}

The junior categories of sports generally represent a particular period of extreme complexity for child and young sports players, since this time coincides precisely with the phase of puberty. During this period, there are great changes to body size and composition, as well as changes to the functional capacity of children and adolescents (Nebigh et al., 2009). In modern soccer, not only strength and muscle power but also height and body mass are important physiological characteristics (Hoff, 2005) and development of these faculties is believed to be closely connected to success at a high level of a given sport (Brodt, Wagner, \& Health, 2008; Secora, Latin, Berg, \& Noble, 2004). Thus, it is crucial to have knowledge about the processes of maturation and growth so that errors in training young sports players in junior categories can be minimized.

Given that the junior levels in soccer are categorized according to chronological age, Malina, Eisenmann, Cumming, Ribeiro, \& Aroso (2004) reported that individuals with advanced maturation obtain, on average, better results in power, strength and speed tests than shown by individuals of the same chronological age with delayed maturation. Moreover, these authors affirmed that these differences were most visible between the ages of 13 and 16 years. In addition, the literature points towards another complicating factor observed among young soccer players: relative age. Musch \& Grondin (2001) defined this factor as the difference that exists among individuals allocated to the same group based on chronological age, and its consequences are known as relative age effects (RAEs). It is worth remembering that these groups are formed based on delimiting the selection year, which is a year formed based on the start and end cutoff dates. For example, if in the year 2012, in an under-14s category, the stipulated start and end cutoff dates are January $1^{\text {st }}$ and December $31^{\text {st }}$, respectively, the selection year comprises all children who were born between January $1^{\text {st }}$ and December $31^{\text {st }}, 1998$. In a system like this, the difference of almost 12 months of age may cause significant anthropometric variances among the young individuals, thus creating a clear advantage for those who were born close to the starting cutoff date (Helsen, Winckel, \& Williams, 2005). Several studies have pointed out that the RAEs in junior soccer are manifested as larger numbers of players who were born close to the starting cutoff date than born close to the end cutoff date (Barnsley, Thompson, \& Legault, 1992; Carling, Le Gall, Reilly, \& Williams, 2009; Folgado, Caixinha, Sampaio, \& Macas, 2006). Several hypotheses have been raised in attempts to explain the main reasons for these results, but no clear explanations have yet been proposed.

In this light, the objectives of the present study were: a) to observe the distribution of dates of birth among junior soccer players over the course of the trimesters of the year; b) to compare the players' anthropometric characteristics and physical performance according to the trimester of birth; and c) to analyze the influence of the maturity offset in the process of selecting young players.

\section{Method}

Sample

Eighty-nine male soccer players participated in this study. They were in the junior categories of a Brazilian soccer club with a great tradition that is affiliated to the Soccer Federation of the State of Rio de Janeiro. These players were in the under-14s category of the years 2008 , 2009 and 2010. In other words, data were gathered from all the players who completed 14 years of age during these three years. All the players who underwent the physical tests had had at least two years of experience of soccer training, were free from injuries that could hinder maximum performance in the evaluations and were receiving training for 5-6 days per week, consisting of approximately 15-18 hours (distributed among physical, technical and tactical training sessions, as well as participating in official matches at least once a week). The participants in this study were performing at the highest competitive level of their respective categories, and were representing the club in the most important competitions, both at state and at national level.

These tests formed part of the routine of evaluations that the players were undergoing. They were conducted every four months and the test protocols were applied to all the categories for at least three years, thus ensuring familiarization with the tests among both the players and the evaluators. The data were then stored for subsequent use by the technical committee. Therefore, it needs to be noted that, although gathered with maximum rigor, the data were not specifically obtained for the present study. To use the database, the researchers informed the club about the objectives and procedures of the study, as well as providing assurances regarding the confidential nature of the individual elements of the data.

\section{Instruments}

To measure sprints of 10 and 30 meters and the Running-based Anaerobic Sprint Test (RAST) (Wol- 
verhampton, United Kingdom), a device containing photoelectric cells was used (Microgate Racetime2, Italy). In the anthropometric evaluation, a Cardiomed stadiometer was used to measure height and a mechanical Filizola scale was used to quantify body mass.

\section{Procedures}

The physical tests were divided over two days: on the first, an anthropometric evaluation was carried out; and on the second, sprints of 10 and 30 meters and RAST. On the first day, height, sitting height and weight were measured in accordance with the ISAK standards (International Society for the Advancement of Kinanthropometry). Sitting height was determined on an anthropometric bench and had the objective of obtaining the height of the trunk and length of the lower limbs.

On the second day of evaluations, to perform the three tests, two pairs of photocells were used at a height of one meter, with one pair located at the starting line and the other pair at the finishing line. The participants began the test in a standing position on the starting line and were instructed to run at maximum speed until passing by the pair of photocells situated at the finishing line. Before performing the tests, the soccer players underwent a warm-up protocol consisting of trotting, short sprints and movements with changes in direction, totaling 10 minutes. After performing the warm-up, each soccer player did two 10 meter sprints with a recovery interval of approximately one minute between each sprint.

Then, they did two 30 meter sprints with a recovery interval of approximately two minutes. Subsequently, the RAST protocol was applied to estimate anaerobic metabolism. RAST consists of performing six maximum-effort sprints of 35 meters each with a recovery of 10 seconds between each run. After carrying out the six sprints, the power $(\mathrm{P})$ of each sprint was obtained by means of the following model:

$$
\mathrm{P}(\text { Watts })=\text { Weight } \mathrm{x} \text { Distance }{ }^{2} / \text { Time }^{3}
$$

In this model, weight was expressed in kilograms, distance in meters and time in seconds. Based on the calculation of $\mathrm{P}$ for each sprint, the variables of maximum power (PMax), i.e. the highest power developed among the six sprints, and the minimum power (PMin), i.e. the lowest power developed among the six sprints, could be obtained. Thus, by using the results obtained, it was possible to calculate another variable described as the fatigue index (FI), given by the following model:

\section{FI (Watts/seconds) $=$ \\ PMax - PMin / Sum of time six sprints}

In this model, PMax and PMin are given in watts and the sum in seconds. This protocol for evaluating anaerobic capacity is well established and has been used by Roseguini, Silva, \& Gobatto (2008), Pellegrinotti et al. (2008), Paradisis, Tziortzis, Zacharogiannis, Smirniotou, \& Karatzanos, (2005) and Zagatto, Beck, \& Gobatto (2009). It is important to emphasize that the recovery interval between physical tests was approximately five minutes.

To evaluate the maturity offset (MO), the model proposed by Mirwald, Baxter-Jones, Bailey, \& Beunen (2002) was used, which predicts how many years the individual is away from his peak height velocity (PHV). If the value obtained is negative, this means that the individual has still not reached his PHV; and if the value is positive, it means that the individual has passed his PHV. The PHV is represented by a MO equal to zero. In this model, the variables that were used were chronological age (CA), weight $(\mathrm{W})$, height $(\mathrm{H})$, length of lower limbs (LLL) and trunk height (TH), and the model that has been described for boys is as follows:

$$
\begin{gathered}
\text { MO (years })=-9,236+[0,0002708 \times(L L L \times \text { TH })]+ \\
{[-0,001663 \times(C A \times L L L)]+[0,007216 \times(\text { CA } \times \text { TH })]+} \\
{[0,02292 \times(\mathrm{W} / \mathrm{H} \times 100)]}
\end{gathered}
$$

This previously described model was chosen because, as well as being a non-invasive method, it also enabled estimation of the age at the PHV, which is currently the indicator most used for longitudinal studies and may be important alternative for determining biological age (Machado, Bonfim, \& Costa, 2009).

The soccer players' dates of birth were organized according to their trimester of birth, based on the FIFA (Fédération Internationale de Football Association) cutoff dates (January $1^{\text {st }}$ and December $31^{\text {st }}$ ) Thus, the trimesters are arranged by January to March; April to June; July to September; and October to December.

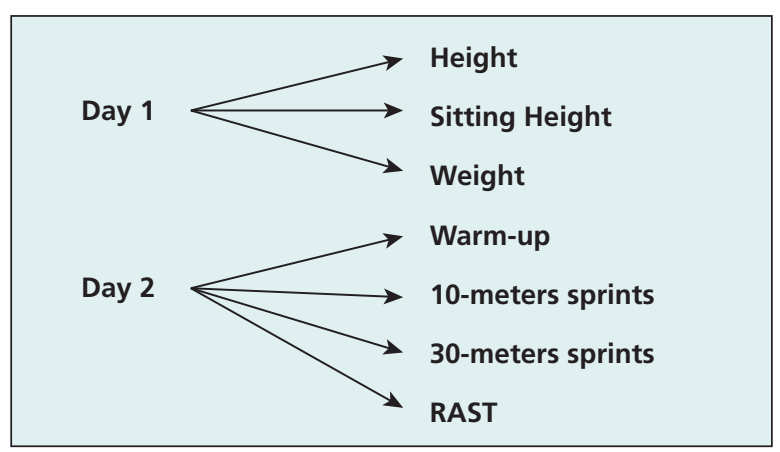

Picture 1. Order of tests. 


\section{Statistical Analysis}

To process the information and describe the results, the subjects were grouped according to their trimester of birth. In descriptive comparisons, central trend measurements (means and standard deviations) were calculated to characterize the groups. The KolmogorovSmirnov normal distribution test was performed, and it indicated that the data presented a tendency towards normality. Analysis of variance (one-way ANOVA) was then performed and, when necessary, Tukey's post-hoc test was used to locate differences among the groups. To analyze the distribution of the sports players according to the trimester of birth, the chi-square test $\left(\chi^{2}\right)$ was used. The significance level used was $p \leq 0.05$.

\section{Results}

The distribution of the dates of birth of the young soccer players in the present study is shown in Table 1. It should be noted that there was great imbalance in the distribution of dates of birth, with especially large presence of individuals born in the first half of the year (and more precisely, in the second trimester).

Table 2 presents the characterization of the soccer players according to their trimester of birth, expressed as means and standard deviations. Through using one-way ANOVA, the means of the anthropometric, physical and maturational characteristics were compared according to the trimester of birth. Statistically significant differences were observed only in compar- ing the maturity offset ( $p \leq 0.005)$. Tukey's post-hoc test showed differences in the comparisons, between the first trimester (1T) and the fourth trimester (4T) ( $p \leq 0.005)$ and between the second trimester $(2 \mathrm{~T})$ and the fourth trimester $(4 \mathrm{~T})(p \leq 0.01)$.

\section{Discussion}

According to the distribution of dates of birth, the results found in the present study show an imbalance over the trimesters of the year, with greater representation of individuals born at the beginning of the year of selection (especially in the second trimester) and smallest representation of those born in the fourth trimester. These results corroborate several studies in the literature on young soccer players (Barnsley et al, 1992; Diaz Del Campo, Vicedo, Villora, \& Jordan, 2010; Folgado et al, 2006; Vincent \& Glamser, 2006). Similarly, Carling et al. (2009) found that approximately $77 \%$ of the under-14s players in their study were born during the first half of the year; and Gil, Gil, Ruiz, Irazusta, \& Irazusta (2007) found that approximately $79 \%$ of the under-14s players were born in the first half of the year. Curiously, the only differential of the present study in relation to other studies is the fact that in this study, a greater percentage of the individuals were found to have been born in the second trimester, and not in the first trimester as had been reported previously (Ashworth \& Heyndels, 2007; Costa et al., 2009; Helsen, Starkes, \& Winckel, 1998).

Table 1. Distribution of young soccer players according birth trimester

\begin{tabular}{|c|c|c|c|c|c|c|c|c|c|c|}
\hline \multicolumn{2}{|c|}{$1 \mathrm{~T}$} & \multicolumn{2}{|c|}{$2 T$} & \multicolumn{2}{|c|}{$3 T$} & \multicolumn{2}{|c|}{$4 T$} & \multirow{2}{*}{ Total } & \multirow[b]{2}{*}{$\chi^{2}$} & \multirow[b]{2}{*}{$p$} \\
\hline$n$ & $\%$ & $n$ & $\%$ & $n$ & $\%$ & $n$ & $\%$ & & & \\
\hline 31 & $34.8 \%$ & 38 & $42.7 \%$ & 10 & $11.2 \%$ & 10 & $11.2 \%$ & 89 & 28.08 & $p \leq 0.001$ \\
\hline
\end{tabular}

Note: $1 \mathrm{~T}=$ First Trimester; $2 \mathrm{~T}=$ Second Trimester; $3 \mathrm{~T}=$ Third Trimester; $4 \mathrm{~T}=$ Forth Trimester.

Table 2. Anthropometric, physical and maturational characteristics of young soccer player according birth trimester: descriptive and one-way ANOVA comparisons

\begin{tabular}{|c|c|c|c|c|c|c|c|c|c|c|}
\hline & \multicolumn{2}{|c|}{$1 \mathrm{~T}$} & \multicolumn{2}{|c|}{$2 T$} & \multicolumn{2}{|c|}{ 3T } & \multicolumn{2}{|c|}{$4 \mathrm{~T}$} & \multicolumn{2}{|c|}{ ANOVA } \\
\hline & Mean & SD & Mean & SD & Mean & SD & Mean & SD & $\mathbf{F}$ & Sig. \\
\hline Age (years) & 14.67 & 0.07 & 14.46 & 0.06 & 14.13 & 0.05 & 13.92 & 0.09 & - & - \\
\hline Weight $(\mathrm{kg})$ & 62.20 & 10.80 & 62.30 & 10.00 & 57.60 & 7.60 & 55.00 & 13.30 & 1.81 & 0.15 \\
\hline Height $(\mathrm{cm})$ & 170.80 & 9.60 & 171.30 & 8.70 & 168.00 & 6.90 & 164.20 & 10.80 & 1.88 & 0.14 \\
\hline Maturity Offset (years) & 1.14 * & 0.75 & $1.06 \S$ & 0.70 & 0.61 & 0.64 & $0.21 * \S$ & 0.92 & 4.87 & 0.00 \\
\hline 10 meters $(s)$ & 1.85 & 0.09 & 1.82 & 0.09 & 1.83 & 0.08 & 1.82 & 0.07 & 0.59 & 0.63 \\
\hline 30 meters (s) & 4.42 & 0.19 & 4.41 & 0.22 & 4.43 & 0.15 & 4.45 & 0.22 & 0.17 & 0.92 \\
\hline Maximum Power (W) & 556.44 & 134.48 & 558.53 & 148.98 & 515.54 & 130.25 & 498.23 & 199.02 & 0.63 & 0.60 \\
\hline Fatigue Index (W/s) & 5.48 & 2.58 & 5.80 & 2.65 & 4.95 & 3.24 & 4.89 & 3.06 & 0.45 & 0.72 \\
\hline
\end{tabular}

Note: $1 \mathrm{~T}$ = First Trimester; $2 \mathrm{~T}=$ Second Trimester; $3 \mathrm{~T}=$ Third Trimester; $4 \mathrm{~T}=$ Forth Trimester; $S D=$ Standard Deviation

* Significant difference $(p \leq 0.005)$; $\S$ Significant difference $(p \leq 0.01)$. 
The results that have been found regarding the predominance of individuals born in the first trimester would reinforce the idea that these individuals would have physical advantages that would be a determining factor in the selection process (Glamser \& Vincent, 2004). However, in none of the physical tests applied in the present study were there any significant differences among individuals born in different trimesters. These results confirm the findings of Malina, Ribeiro, Aroso, \& Cumming (2007), who also did not observe any clear trend of advantage in physical characteristics among the under-14s soccer players born in the first trimester, in comparison with individuals in the fourth trimester. In the same way, Carling et al. (2009) did not observe any significant differences in the results from physical tests on young soccer players in the under-14s category when the same type of comparison according to trimester of birth was made.

In addition to physical characteristics, anthropometric characteristics (weight and height) have also been used to explain why individuals born in the first trimester of the year would be favored over those born in the fourth trimester, during the selection process. Helsen, Starkes, \& Winckel (2000) highlighted that individuals born in the first months of the year have advantages in these characteristics, in comparison with those born in the final months of the year. In the present study, these relationships established in the literature were not observed either for weight or for height, even though there was a clear trend towards selecting those born in the first months of the year. These results suggest that, in a highly selected group in this age category, the fact that an individual was born in the first or last trimester of the year of selection does not necessarily mean that this individual has advantages or disadvantages in physical performance characteristics (Carling et al., 2009).

However, Delorme \& Raspaud (2009) demonstrated that, among under-14s basketball players, a RAE was found (with greatest selection of those born in the second trimester of the year), and statistically significant differences were observed in comparing heights according to the trimester of birth (such that those born in the first and fourth trimesters presented the highest and lowest mean values, respectively). Furthermore, in a study on young soccer players in the same age category, Hirose (2009) found significant differences of the same type, in relation to the RAE (greater occurrence of individuals born in the first trimester) and in relation to anthropometric characteristics. This author reported that both for weight and for height, the individuals born in the fourth trimester of the year presented the lowest mean values. Similarly,
Carling et al. (2009) showed that soccer players in the same age category born in the first trimester of the year had a significant height advantage. Although the results found in the present study do not reproduce what is described in the literature, it seems that height has a relationship with the trimester of birth and that it has some influence on the selection process for young sports players. Sherar, Baxter-Jones, Faulkner, \& Russel (2007) affirmed that highly selected individuals presented significantly greater heights than seen among non-selected individuals.

Another important factor that needs to be observed during the process of selecting young sports players is biological maturation. Some studies have proposed that individuals with advanced maturation tend to be favored and classified as "talented", which could then be correlated with the predominance of individuals born in the first trimester in competitive sports teams (Cobley, Baker, Wattie, \& McKenna, 2009; Folgado et al., 2006; Vaeyens, Philippaerts, \& Malina, 2005). Nevertheless, no significant differences in biological maturation were observed in relation to the trimesters of birth among young soccer players in the under-14s category (Carling et al., 2009; Hirose, 2009). However, the present study obtained results that corroborate with those previously mentioned and confirmed the theory that born during the first trimester of the year have a maturational advantage, even though these data were not reflected in significant physical advantages.

The literature provides data that support the idea that biological maturation has a clear relationship with performance in motor tests, anthropometric characteristics and strength gain, for example (Malina et al., 2004; Neu, Rauch, Rittweger, Manz, \& Schoenau, 2002). However, there is some doubt regarding maturational differences between individuals in different birth trimesters and whether this could be associated with advantages in the selection process.

Thus, it could appear that there is a conflict in the information that the present study provides theoretical support that reinforces the role of maturation in development of physical faculties, with differences in maturation according to the trimester of birth, but without demonstrating differences in physical and anthropometric characteristics. However, interpretation of the PHV in the lives of children and adolescents can help to explain the results found. According to Beunen \& Malina (1988) and Yague \& De La Fuente (1998), $\mathrm{PHV}$ is a biological marker that is also used to follow up variations in motor performance over the course of the child or adolescent's development. In a longitudinal study on young soccer players, Philippaerts et al. 
(2006) demonstrated that performance in speed tests tends to stabilize, especially after the PHV has been passed. Machado et al. (2009) confirmed this idea by demonstrating that among individuals with a more advanced maturational rate (individuals who had already passed their PHV), no significant differences were observed in relation to performance in speed tests. However, when these observations were made among individuals with a maturational rate close to the PHV or at a time prior to the PHV, significant differences in performance were observed. These studies might explain the results found in the present study, since it can be seen from Table 2 that the mean maturation rate among the individuals in the four trimesters was positive, thus showing that the PHV had already occurred. Therefore, despite the significant differences in maturation rate over the course of the trimesters of the year, it would not be imprudent to expect the results that were found, regarding the physical tests.

Several authors have reported that these results in which a greater proportion of the individuals were born at the beginning of the year are closely connected with the high level of abandonment among those born in the final months of the year, since these individuals would encounter a great number of negative situations and failures in the sport (Barnsley \& Thompson, 1988; Delorme, Boiche, \& Raspaud, 2010a, 2010b; Delorme, Chalabaev, Raspaud, 2011; Helsen et al., 1998). From the discussion put forward here, it is possible to hypothesize that these high levels of abandonment of the sport may be related to the anthropometric disadvantages studied here, even though the present study does not provide results that fully prove this. It also has to be borne in mind that no theoretical references were found that proposed such a comparison between abandonment of a sport and physical characteristics. Moreover, Delorme et al. (2011) reported that this rate of abandonment decreased from the age of 15 years onwards, a time that could coincide with stabilization of performance in relation to some physical faculties (Machado et al., 2009), with a tendency towards attenuation of maturational differences (Delorme, Boiche, \& Raspaud, 2009; Malina et al., 2000; Musch \& Grondin, 2001).

\section{Conclusion}

From the results found and the discussion put forward, it can be concluded that among high-level Brazilian young soccer players who have gone through several selection stages, the trimester of birth may not have a relationship with physical performance and anthropometric characteristics, even if there are differences in biological maturation. Obviously, the present study has methodological limitations, such as a small sample in relation to the number of young soccer players within this sports context, even though the individuals in this study can be considered to be the national elite of their category. Furthermore, the absence of data regarding the soccer players' body composition (e.g. muscle mass) meant that no in-depth knowledge on certain characteristics could be obtained. It is suggested that new studies with the same purpose should be carried out in order to observe whether the results presented here are reproducible, especially among individuals with lower maturational rates (i.e. before they pass the PHV), so that the behavior of the variables analyzed can be observed before the performance stabilization period. It is important to emphasize that the selection processes for young sports talent must take into account all the maturational characteristics of these children and adolescents, and that the selection should be based less on subjective criteria, with regard to technical and physical issues. In the same way, throughout this complex phase of selecting young sports players, biological individuality must be respected and taken into consideration in the final judgment of the process, thus avoiding exclusion of individuals with delayed maturation who have abilities and the possibility in the future of reaching the professional level of the sport. 


\section{REFERENCES}

Ashworth, J., \& Heyndels, B. (2007). Selection bias and peer effects in team sports: The effect of age grouping on earnings of German soccer players. Journal of Sports Economics, 8(4), 355-377.

Barnsley, R. H., \& Thompson, A. H. (1988). Birthdate and success in minor hockey: The key to the NHL. Canadian Journal of Behavioural Sciece, 20(2), 167-176.

Barnsley, R. H., Thompson, A. H., \& Legault, P. (1992). Family planning: Football style. The relative age effect in football. International Review for the Sociology of Sport, 27(1), 77-88.

Beunen, G., \& Malina, R. M. (1988). Growth and physical performance relative to the timing of the adolescent spurt. Exercise and Sport Sciences Reviews, 16(1), 503-540.

Brodt, V., Wagner, D. R., \& Heath, E. M. (2008). Countermovement vertical jump with drop step is higher than without in collegiate football players. Journal of Strength and Conditioning Research, 22(4), 13821385 .

Carling, C., Le Gall, F., Reilly, T., \& Williams, A. M. (2009). Do anthropometric and fitness characteristics vary according to birth date distribution in elite youth academy soccer players? Scandinavian Journal of Medicine \& Science in Sports, 19(1), 3-9.

Cobley, S., Baker, J., Wattie, N., \& McKenna, J. (2009). Annual agegrouping and athlete development: A meta-analytical review of relative age effects in sport. Sports Medicine, 39(3), 235-256.

Costa, V. T., Simim, M. A., Noce, F., Costa, I. T., Samulski, D. M., \& Moraes, L. C. (2009). Comparison of relative age of elite athletes participating in the 2008 Brazilian soccer championship series A and B. Motricidade, 5(3), 13-17.

Delorme, N., \& Raspaud, M. (2009). The relative age effect in young French basketball players: A study on the whole population. Scandinavian Journal of Medicine and Science in Sports, 19(2), 235-242.

Delorme, N., Boiche, J., \& Raspaud, M. (2009). The relative age effect in elite sport: The French case. Research Quarterly for Exercise \& Sport, 80(2), 336-344.

Delorme, N., Boiche, J., \& Raspaud, M. (2010a). Relative age and dropout in French male soccer. Journal of Sports Sciences, 28(7), 717-722.

Delorme, N., Boiche, J., \& Raspaud, M. (2010b). Relative age effect in female sport: A diachronic examination of soccer players. Scandinavian Journal of Medicine \& Science in Sports, 20(3), 509-515.

Delorme, N., Chalabaev, A., \& Raspaud M. (2011). Relative age is associated with sport dropout: Evidence from youth categories of French basketball. Scandinavian Journal of Medicine \& Science in Sports, 21(1), 120-128.

Diaz Del Campo, D. G., Vicedo, J. C. P., Villora, S. G., \& Jordan, O. R. C. (2010). The relative age effect in youth soccer players from Spain. Journal of Sports Science and Medicine, 9(2), 190-198.

Folgado, H. A., Caixinha, P. F., Sampaio, J., \& Macas, V. (2006). Efeito da idade cronologica na distribuicao dos futebolistas por escalões de formação e pelas diferentes posições especificas. Revista Portuguesa de Ciências do Desporto, 6(3), 349-355.

Gil, S. M., Gil, J., Ruiz, F., Irazusta, A., \& Irazusta, J. (2007). Selection of young soccer players in terms of anthropometric and physiological factors. Journal of Sports Medicine and Physical Fitness, 47(1), 25-32.

Glamser, F. D., \& Vincent, J. (2004). The relative age effect among elite American youth soccer players. Journal of Sport Behavior, 27(1), 31-38.

Helsen, W., Starkes, J. L., \& Winckel, J. (1998). The influence of relative age in success and dropout in male soccer players. American Journal of Human Biology, 10(6), 791-798

Helsen, W., Starkes, J. L., \& Winckel, J. (2000). Effect of a change in selection year on success in male soccer player. American Journal of $\mathrm{Hu}$ man Biology, 12(6), 729-735.

Helsen, W., Winckel, J., \& Williams, A. M. (2005). The relative age effect in youth soccer across Europe. Journal of Sports Sciences, 23(6), 629-636.

Hirose, N. (2009). Relationships among month-birth distribution, skeletal age and anthropometric characteristics in adolescent elite soccer players. Journal of Sports Sciences, 27(11), 1159-1166.

Hoff, J. (2005). Training and testing physical capacities for elite soccer players. Journal of Sports Sciences, 23(6), 573-582.
Machado, D. L. R., Bonfim, M. R., \& Costa, L. T. (2009). Pico de velocidade de crescimento como alternativa para classificação maturacional associada ao desempenho motor. Revista Brasileira de Cineantropometria \& Desempenho Humano, 11(1), 14-21.

Malina, R. M., Eisenmann, J. C., Cumming, S., Ribeiro, B., \& Aroso, J. (2004). Maturityassociated variation in the growth and functional capacities of youth football (soccer) players 13-15 years. European Journal of Applied Physiology, 91(5-6), 555-562.

Malina, R. M., Peña Reyes, M. E., Eisenmann, J. C., Horta, L., Rodrigues, J., \& Miller, R. (2000). Height, mass, and skeletal maturity of elite Portuguese soccer players 11-16 years of age. Journal of Sports Sciences, 18(9), 685-693.

Malina, R. M., Ribeiro, B., Aroso, J., \& Cumming, S. P. (2007). Characteristics of youth soccer players aged 13-15 years classified by skill level. British Journal of Sports Medicine, 41(5), 290-295.

Mirwald, M. L., Baxter-Jones, A. D. G., Bailey, D. A., \& Beunen, G. P. (2002). An assessment of maturity from anthropometric measurements. Medicine and Science in Sports and Exercise, 34(4), 689-694.

Musch, J., \& Grondin, S. (2001). Unequal competition as an impediment to personal development: A review of the relative age effect in sport. Developmental Review, 21(2), 147-167.

Nebigh, A., Rebai, H., Elloumi, M., Bahlous, A., Zouch, M., Zaouali, M., Alexandre, C., Sellami, S., \& Tabka, Z. (2009). Bone mineral density of young boy soccer players at different pubertal stages: Relationships with hormonal concentration. Joint Bone Spine, 76(1), 63-69.

Neu, C. M., Rauch, F., Rittweger, J., Manz, F., \& Schoenau, E. (2002). Influence of puberty on muscle development at the forearm. American Journal of Physiology - Endocrinology and Metabolism, 283(1), 103-107.

Paradisis, G. P., Tziortzis, S., Zacharogiannis, E., Smirniotou, A., \& Karatzanos, L. (2005). Correlation of the running-based anaerobic sprint test (RAST) and performance on the $100 \mathrm{~m}, 200 \mathrm{~m}$ and $400 \mathrm{~m}$ distance tests. Journal of Human Movement Studies, 49(2), 77-92.

Pellegrinotti, I. L., Daniel, J. F., Cielo, F. B. L., Cavaglieri, C. R., Neto, J. B., Montebelo, M. I. L., \& Cesar, M. C. (2008). Análise da potência anaeróbia de jogadores de futebol de três categorias, por meio do "teste de velocidade para potência anaeróbia” (TVPA) do Running-Based Anaerobic Sprint Test (RAST). Arquivos em Movimento, 4(2), 3-15.

Philippaerts, R. M., Vaeyens, R., Janssens, M., Renterghem, B., Matthys, D., Craen, R., Bourgois, J., Vrijens, J., Beunen, G., \& Malina, R. M. (2006). The relationship between peak height velocity and physical performance in youth soccer players. Journal of Sports Sciences, 24(3), 221-230.

Roseguini, A. Z., Silva, A. S. R., \& Gobatto, C. A. (2008). Determinações e relações dos parâmetros anaeróbios do RAST, do limiar anaeróbio e da resposta lactacidemica obtida no inicio, no intervalo e ao final de uma partida oficial de handebol. Revista Brasileira de Medicina do Esporte, 14(1), 46-50.

Secora, C. A., Latin, R. W., Berg, K. E., \& Noble, J. M. (2004). Comparison of physical and performance characteristics of NCAA Division I football players: 1987 and 2000. Journal of Strength and Conditioning Research, 18(2), 286-291.

Sherar, L. B., Baxter-Jones, A. D. G., Faulkner, R. A., \& Russel, K. W. (2007). Do physical maturity and birth date predict talent in male youth ice hockey players? Journal of Sports Sciences, 25(8), 879-886.

Vaeyens, R., Philippaerts, R. M., \& Malina, R. M. (2005). The relative age effect in soccer: A match-related perspective. Journal of Sports Sciences, 23(7), 747-756.

Vincent, J., \& Glamser, F. D. (2006). Gender differences in the relative age effect among US Olympic development program youth soccer players. Journal of Sports Sciences, 24(4), 405-413.

Yagüe, P. H., \& De La Fuente, J. M. (1998). Changes in height and motor performance relative to peak height velocity: A mixed-longitudinal study of Spanish boys and girls. American Journal of Human Biology, 10(5), 647-660.

Zagatto, A. M., Beck, W. R., \& Gobatto, C. A. (2009). Validity of the running anaerobic sprint test for assessing anaerobic power and predicting short-distance performances. Journal of Strength and Conditioning Research, 23(6), 1820-1827. 